\title{
Management Analysis of Industrial Production Losses by the Design of Experiments, Statistical Process Control, and Capability Indices
}

\author{
Djida Bounazef $^{1,2}$, Smain Chabani ${ }^{1}$, Abdelhafid Idir ${ }^{1}$, Mokhtar Bounazef ${ }^{3}$ \\ ${ }^{1}$ HEC, Commercial Graduate School of Algiers, Algiers, Algeria \\ ${ }^{2}$ Abderrahmane Mira University of Bejaia, Bejaia, Algeria \\ ${ }^{3}$ Djillali Liabes University of Sidi Bel Abbes, Sidi Bel Abbes, Algeria \\ Email: djida.bounazef@ymail.com, incsmachab@gmail.com, a_idir@yahoo.com, Bounazef@yahoo.com
}

Received November 21, 2013; revised December 23, 2013; accepted January 10, 2014

Copyright (C) 2014 Djida Bounazef et al. This is an open access article distributed under the Creative Commons Attribution License, which permits unrestricted use, distribution, and reproduction in any medium, provided the original work is properly cited. In accordance of the Creative Commons Attribution License all Copyrights (C) 2014 are reserved for SCIRP and the owner of the intellectual property Djida Bounazef et al. All Copyright (C) 2014 are guarded by law and by SCIRP as a guardian.

\begin{abstract}
The machine stops caused by various breakdowns, rupture of raw materials, production changes, scheduled maintenance and stops related to human resources management generate an important production loss in the company. Our case study is done in a company that manufactures polyethylene pipes with eight production lines. They stop frequently because they undergo external control factors and noise factors. The method of experimental design that relies on statistical surveys is applied to production loss allows us to observe the action of each factor on the loss of production and their interactions of these factors combined in pairs on this process. Analysis of results shows the dominance of controllable or uncontrollable factor on the loss of production. This is illustrated by response surfaces and ISO responses lines were derived by mathematical modelling. Solutions are proposed to improve continuous production, reduce waste and scrap and therefore increase profitability of company.
\end{abstract}

\section{KEYWORDS}

Design of Experiments; Production Losses; Response Surfaces; Polynomial Modelling; Integrated Management System

\section{Introduction}

The reduction of industrial waste is the major preoccupation of an integrated management system [1,2] which includes the environmental management system [3], the system of quality management $[4,5]$ and the management system of health, security and work [6,7]. These systems are applied within the company following the requirements of ISO 9001:2000 code 4, until 8.5.3, of ISO 14001:2004 and OHSAS 18001:2007 to achieve optimal production by minimising work stops caused by various technical and operational reasons. This integrated management system [8-10] is applied to the production lines at the beginning when checking the quality of raw materials until the end when storing finished products to contribute in reducing production losses and obtaining finished quality products. For this, the checks are carried out to the quality of raw materials, during the production process, for finished products and after handling and storage. However, the implementation of integrated management system is not sufficient in itself, in parallel it is necessary to reduce production stops caused by mechanical and electrical problems, by human resources management, by the supplies disruption of raw materials and others. To know the influence of each breakdown reason of machinery at each production line, a data record has been established for a period of one year. These causes were grouped into 3 categories that encompass these machine stops into the same types. These categories are the accidental stops, the downtimes due to machine maintenance and human resource management and the third is stops due to raw material and finished products. The stops are 
estimated in work hours whereas the loss of production is calculated as a percentage relative to maximum production. The three factors of production stops act simultaneously on the loss of production. The application of the method of design of experiments shows how each factor acts on the loss of production by a mathematical modelling and therefore what measures should be taken to avoid this phenomenon.

\section{Statistical Reports of the Causes of Production Stops}

Modelling by design of experiments method analyses the continuous production process of polyethylene pipes by measuring causes of production losses (waste) caused by the steering factors and noise factors. The causes of machines downtimes that increase the percentage of production loses (inducing the waste) are defined by three parameters on the Ishikawa diagram (Figure 1).

The production process is composed of eight independent production lines; their stops are caused separately by the same reasons and therefore act on production losses (lack of production).

Table 1 shows the distribution of hours of production losses by types and production lines. The accidental stops are designed by $\mathrm{X}_{1}$, the scheduled stops are designed by $\mathrm{X}_{2}$ and the stops due to raw material and finished products are designed by $\mathrm{X}_{3}$. Table 1 is called matrix of experiments, it contains column 6 that means losses of production expressed in percent. They designate the responses Y. We see that the line E records the high numbers of hours of accidental stops with 2731.83 hours and human resources management stops with 1085.67 hours, but it is the line $\mathrm{H}$ that has the high number of Stops due to raw material and finished products with 9703.75 hours. The greatest loss of production is recorded on line $\mathrm{E}$ with $66.18 \%$ compared to optimal production. This is the line that stores the most breakdowns and stops. However, it is the line $\mathrm{C}$ that has the smallest losses of production with $20 \%$.

\section{Phenomenon Analysis of Machines Stops by Design of Experiments Method}

The loss of industrial production caused mainly by different stops responds to a mathematical law in polynomial form. This polynomial is a sum of monomials that are composed of coefficient $a_{i}$ (called parameter effect) multiplied by the value of the parameter designated by $x_{i}$. In our study, $x_{1}$ is letter that represents accidental stops, $x_{2}$ is letter that represents maintenance and human resources management stops, and $x_{3}$ represents stops due to raw material and finished products. In the polynomial, there are monomials that designate the interactions between the parameters that influence the result; these pa- rameters are appointed by $x_{i} x_{j}$ and $x_{i i}^{2}(i, j=1,2,3)$; they must be multiplied by the value of the effect $a_{i j}$. This sum of these monomials represents the response " $y$ " i.e. the loss of production:

$$
\begin{aligned}
y= & a_{0}+a_{1} x_{1}+a_{2} x_{2}+a_{3} x_{3}+a_{12} x_{1} x_{2}+a_{13} x_{1} x_{3} \\
& +a_{23} x_{2} x_{3}+a_{11} x_{1}^{2}+a_{22} x_{2}^{2}+a_{33} x_{3}^{2}
\end{aligned}
$$

In the expression 1, the parameters values are coded values. Generally they are coded because their units and their scales that affect the response " $y$ " are different. For each parameter, we denote by $(-1)$ the minimum value, and by (+1) the maximum value; the intermediate values are calculated by the following formula:

$$
x_{i}=\frac{u_{i}-\left(\frac{u_{\text {min }}+u_{\max }}{2}\right)}{\left(\frac{u_{\max }-u_{\min }}{2}\right)}
$$

where: $U_{\min }$ is minimal value of parameter, $U_{\max }$ : is maximal value of parameter, $U_{i}$ is value to be encoded, and $x_{i}$ is coded value. Table 2 shows these coded values.

The matrices calculation allows us to obtain the effects values $a_{i}$ of parameters by forming 10 different equations from equation 1 by replacing the $x_{i}$ parameters by values from Table 1 , we could obtain the 10 coefficients $a_{i, j}$ by the following formula:

$$
a=\left(X^{t} X\right)^{-1} X^{t} Y
$$

Substituting the values of $a_{i, j}$ into Equation (1), the production losses caused by three types of stops is modelled by the following expression:

$$
\begin{aligned}
y= & 37.8259+6.81969 x_{1}+1.90399 x_{2}+2.03238 x_{3} \\
& +1.30382 x_{1} x_{2}-8.78769 x_{1} x_{3}-2.8691 x_{2} x_{3} \\
& -1.42286 x_{1}^{2}+2.72951 x_{2}^{2}+0.44013 x_{3}^{2}
\end{aligned}
$$

\section{Results Interpretation}

The interpretation is subdivided in two essential parts, the first consists to analyse causes of production stops of 8 lines of production using design of experiments method, while the second consists to analyse waste generated by frequency of production stops using statistical process control.

\section{Analysis of Production Stops Effects by Experiments Design Method}

Equation (4) allows us not only to find the real loss values of production " $y$ " listed in Table 2, but other values included between the maximum and minimum losses. This is a predictive and descriptive model. This is shown by the estimators of adjusted descriptive quality $R_{\text {adjust }}^{2}$ and predictive quality $Q^{2}$ of model. Both $R_{\text {adjust }}^{2}$ and $Q^{2}$ 


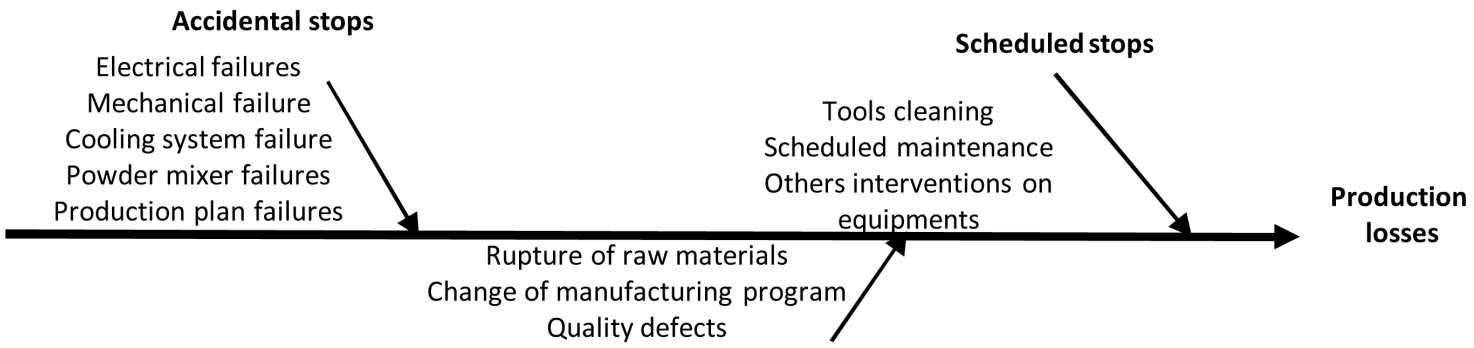

Figure 1. Stops due to raw material and finished products.

Table 1. Hours of production losses per line.

\begin{tabular}{cccccc}
\hline $\mathrm{N}^{\circ}$ & Lines & $\begin{array}{c}\text { Accidental stops } \\
{[\mathrm{H}]\left(\mathrm{X}_{1}\right)}\end{array}$ & $\begin{array}{c}\text { Maintenance and human } \\
\text { resources management stops } \\
{[\mathrm{H}]\left(\mathrm{X}_{2}\right)}\end{array}$ & $\begin{array}{c}\text { Stops due to raw material and } \\
\text { finished products } \\
{[\mathrm{H}]\left(\mathrm{X}_{3}\right)}\end{array}$ & $\begin{array}{c}\text { Production losses } \\
{[\%](\mathrm{Y})}\end{array}$ \\
\hline 1 & Line A & 220.8 & 798.92 & 988.08 & 22.49 \\
2 & Line B & 1692.8 & 844.08 & 1048 & 40 \\
3 & Line C & 153.67 & 815.75 & 795.08 & 20 \\
4 & Line D & 1891.75 & 669.42 & 1291.83 & 43.27 \\
5 & Line E & 2731.83 & 1085.67 & 2074.75 & 66.18 \\
6 & Line F & 1393.5 & 876.92 & 1515.58 & 42.52 \\
7 & Line G & 741.88 & 859.67 & 779.17 & 26.74 \\
8 & Line H & 1690.33 & 795.61 & 9703.75 & 41.26 \\
\hline
\end{tabular}

Table 2. Coded values of several stops of machines.

\begin{tabular}{cccccc}
\hline $\mathrm{N}^{\circ}$ & Lines & $\begin{array}{c}\text { Coded accidental stops } \\
\left(\mathrm{X}_{1}\right)\end{array}$ & $\begin{array}{c}\text { Coded maintenance and human } \\
\text { resources management stops } \\
\left(\mathrm{X}_{2}\right)\end{array}$ & $\begin{array}{c}\text { Coded values of stops due to raw } \\
\text { material and finished products } \\
\left(\mathrm{X}_{3}\right)\end{array}$ & $\begin{array}{c}\text { Production losses } \\
(\mathrm{Y})\end{array}$ \\
\hline 1 & Line A & -0.9479241 & -0.37777778 & -0.95318323 & -0.89216111 \\
2 & Line B & 0.19397555 & -0.16079279 & -0.93975515 & -0.13382417 \\
3 & Line C & -1 & -0.29691291 & -0.99643457 & -1 \\
4 & Line D & 0.34831042 & -1 & -0.8851128 & 0.00779558 \\
5 & Line E & +1 & +1 & -0.70966029 & +1 \\
6 & Line F & -0.03820554 & -0.003003 & -0.83497039 & -0.02468601 \\
7 & Line G & -0.54369783 & -0.08588589 & -1 & -0.70809874 \\
8 & Line H & 0.19205945 & -0.39368168 & +1 & -0.07925509 \\
\hline
\end{tabular}

values are numbers usually between $-\infty$ and 1 . Values close to 1 for both $R_{\text {adjust }}^{2}$ and $Q^{2}$ indicate very good model with excellent predictive result. In our case $R_{\text {adjust }}^{2}=0.903$ and $Q^{2}=0.863$. The first estimator reflects the contribution of the model in the restitution of the observed response and the second estimated coefficient reflects the ability of the model to predict response without making statistical measurements or experiments. To illustrate these results, the Figure 2 shows the deviations of measurement points relative to bisector.

The details of deviations are shown in Table 3 where one sees that the maximum deviation is estimated to $7.9 \%$ in measurement 7. The Student test shows us if the variable $x_{i}$ or the interaction $x_{i, j}$ associated with $a_{i, j}$ affects response " $y$ " or not. For this, one calculates the coefficient $t_{i}$ of Student as follows:

$$
t_{i}=\frac{\left|a_{i}\right|}{s_{i}}
$$

With $s_{i}^{2}$ is variance of effects; it is calculated by following:

$$
s_{i}^{2}=\frac{s^{2}}{n}
$$

where $s^{2}$ is estimator of polynomial effects; it is calculates by this formula:

$$
s^{2}=\frac{1}{n-p} \sum e_{i}^{2}
$$

Here, $n$ is equations number obtained by combinations of values of $x_{i, j}$ from Table 1 , it is equal to $3^{3}=27$ (full factorial design), and $p$ is number of modelling coeffi- 


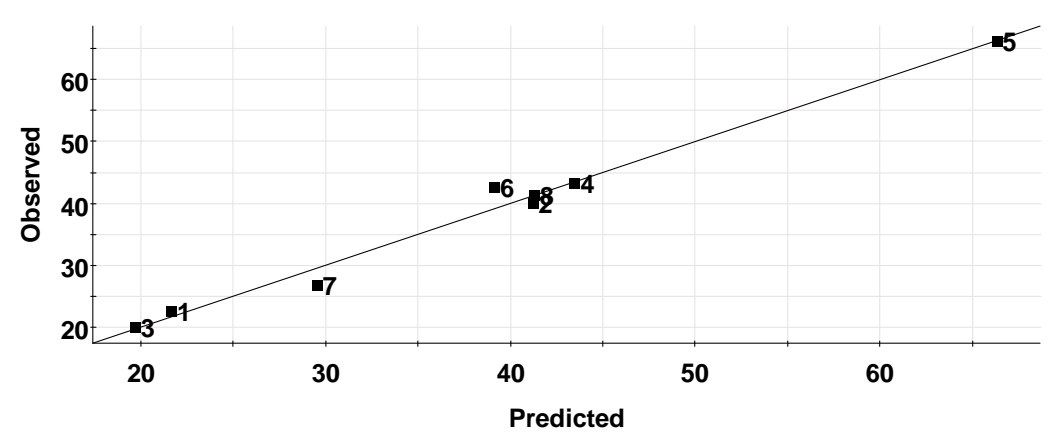

Figure 2. Observed vs. Predicted plot.

Table 3. Deviations between predicted and observed values.

\begin{tabular}{cccc}
\hline $\mathrm{N}^{\circ}$ & Observed & Predicted & Difference \\
\hline 1 & 22.49 & 21.6865 & 0.803453 \\
2 & 40 & 41.2669 & -1.26685 \\
3 & 20 & 19.7343 & 0.265732 \\
4 & 43.27 & 43.4725 & -0.202545 \\
5 & 66.18 & 66.331 & -0.151001 \\
6 & 42.52 & 39.1532 & 3.36685 \\
7 & 26.74 & 29.5363 & -2.79629 \\
8 & 41.26 & 41.2793 & -0.0193405 \\
\hline
\end{tabular}

cients, it is equal to 10 (see Equation (1)). The comparison between $t_{\text {crit }}$ taken from Student table for risk $\alpha=$ 0.05 and freedom degree $v=17$, shows that all " $t_{i}$ " are higher than $t_{\text {crit }}=0.689$, it means that all variables $x_{i, j}$ influence the response " $y$ ", i.e. the loss of production (Table 4).

Equation (4) allows working simultaneously the three parameters in the field of work but we cannot interpret it graphically. However, we vary two parameters while leaving unchanged the third parameter $\left(x_{3}\right)$.

\section{Production Losses According Accidental Stops When $x_{2}$ and $x_{3}$ Are Middle Values}

To observe how the losses of production vary according one parameter, one gives to 2 others parameters in Equation (4) permanent middle values. We can then plot the variation of production losses according one of 3 parameters. The statistics collected during the production indicate that while stabilising the production losses due to raw materials and finished products as well as maintenance to their middle values $\left(x_{2}=877.7\right.$ hours, $x_{3}=$ 5241.6 hours), one reaches the maximum value of $40.5 \%$ of production losses at 900 hours of accidental stops. The mathematical modelling decreases these losses to $34.3 \%$ at 2730 hours (Figure 3 ). When $x_{1}$ exceeds the value of 900 hours, $x_{2}$ and $x_{3}$ are statistically acting on the model and are decreasing production losses.
Table 4. Student coefficients.

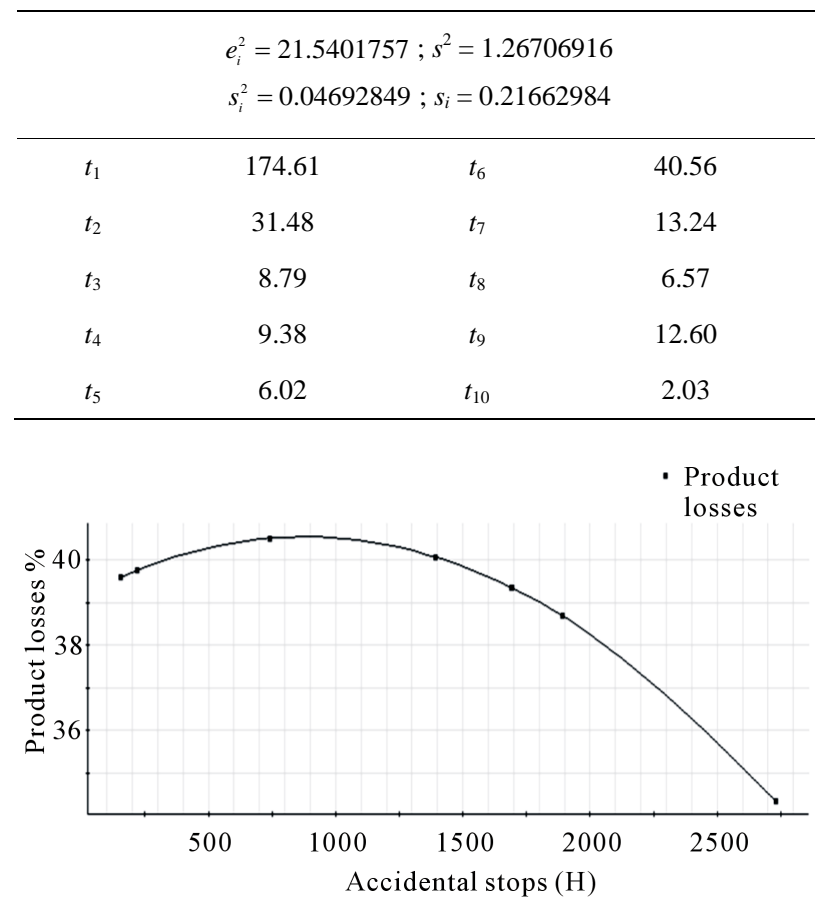

Figure 3. Graph of production losses according accidental stops.

\section{Production Losses According Maintenance and Human Resources Management Stops When $x_{1}$ and $x_{3}$ Are Middle Values}

Maintaining accidental stops $x_{1}$ and stops due to raw material and finished products $x_{3}$ constant respectively at 1476.40 hours and 5241.6 hours, one varies only $x_{2}$ from its minimum value to its maximum value, we obtain a minimal loss of production of $39.8 \%$ for $x_{2}=860$ hours (Figure 4).

This means that the parameter $x_{2}$ has a positive influence in reducing production losses in the model (4), but from $x_{2}=860$ hours, factors $x_{1}$ and $x_{3}$ are more influential than $x_{2}$. This explains why the curve increases until production losses of $50.2 \%$ for $x_{2}=1090$ hours. 


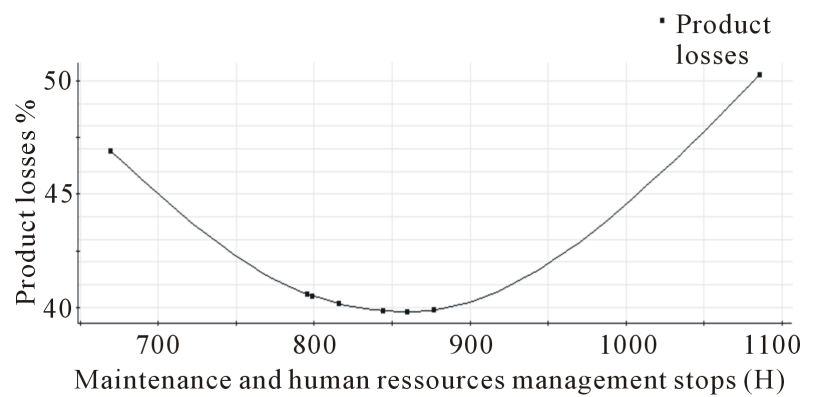

Figure 4. Graph of production losses according maintenance and human resources management stops.

\section{Production Losses According Stops Due to Raw Material and Finished Products When $x_{1}$ and $x_{2}$ Are Middle Values}

When we leave constant $x_{1}=1476.40$ hours and $x_{2}=$ 877.70 hours (middle values), we note that the minimum losses of production is quickly reached at $30.8 \%$ for $x_{3}=$ 3260 hours when the curve decreases. This shows that from this minimum, the factors $x_{1}$ and $x_{2}$ are increasing the response " $y$ " (production losses) when $x_{3}$ varies from its minimum value to maximum value (Figure 5).

\section{Results Interpretation When $x_{1}$ and $x_{2}$ Are Varied Together}

For this, one gives to third parameter $x_{3}$ an invariable value and one changes the 2 other from their minimum value to their maximum value. One can plot response surfaces in three dimensions and curves iso-responses in two dimensions to illustrate the action of two parameters simultaneously on the production losses.

\section{When $x_{3}$ Is Equal at the Low Value ( $x_{3}=779.17$ Hours)}

In this case, the response surface is concave rectangular form; it shows parallel areas of production losses mainly when accidental stops $\left(x_{1}\right)$ and stops caused by maintenance and management of human resources $\left(x_{2}\right)$ are high (Figure 6).

When accidental stops are less than 1500 hours, these areas are parallel to the axis of $x_{2}$. It shows that accidental stops act very low in the model response. All this is visible on curves ISO response, where one notes that the losses of production remains relatively constant between $20.8 \%$ and $24.2 \%$ for stops due to maintenance and management of human resources between 675 hours and 937.5 hours. From 1330 hours of accidental stops that the increase of $x_{2}$ increases clearly the production losses.

\section{When $x_{3}$ Is Equal at the Middle Value ( $x_{3}=5241.60$ Hours)}

When $x_{3}$ takes the middle value of 5241.6 hours, the ma-

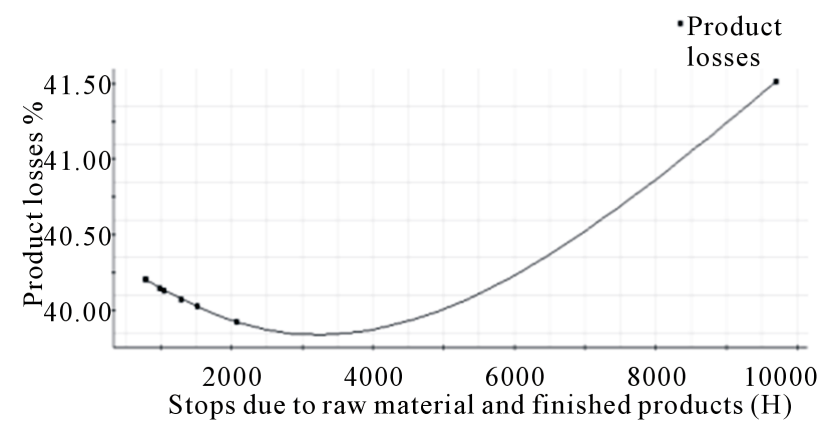

Figure 5. Graph of production losses according stops due raw material and finished products.

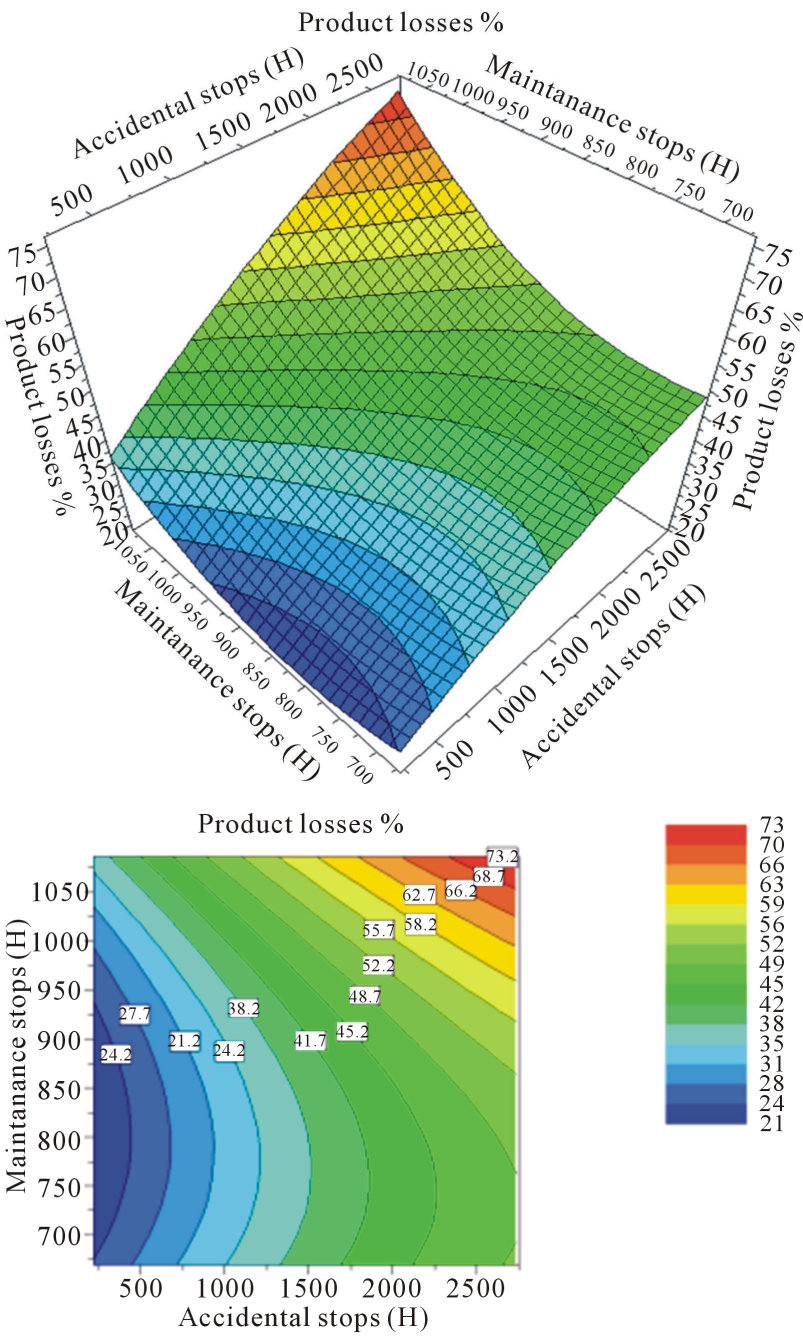

Figure 6. Response surface and ISO response curves when $x_{3}$ is low.

thematical model (4) presents responses surface as a saddle of horse (Figure 7). Its complexity shows how the simultaneous influence of $x_{1}$ and $x_{2}$ acts on production losses of finished products. The projection of the response surface on the lower plane gives ISO responses curves that's the central part is in the form of four ten- 

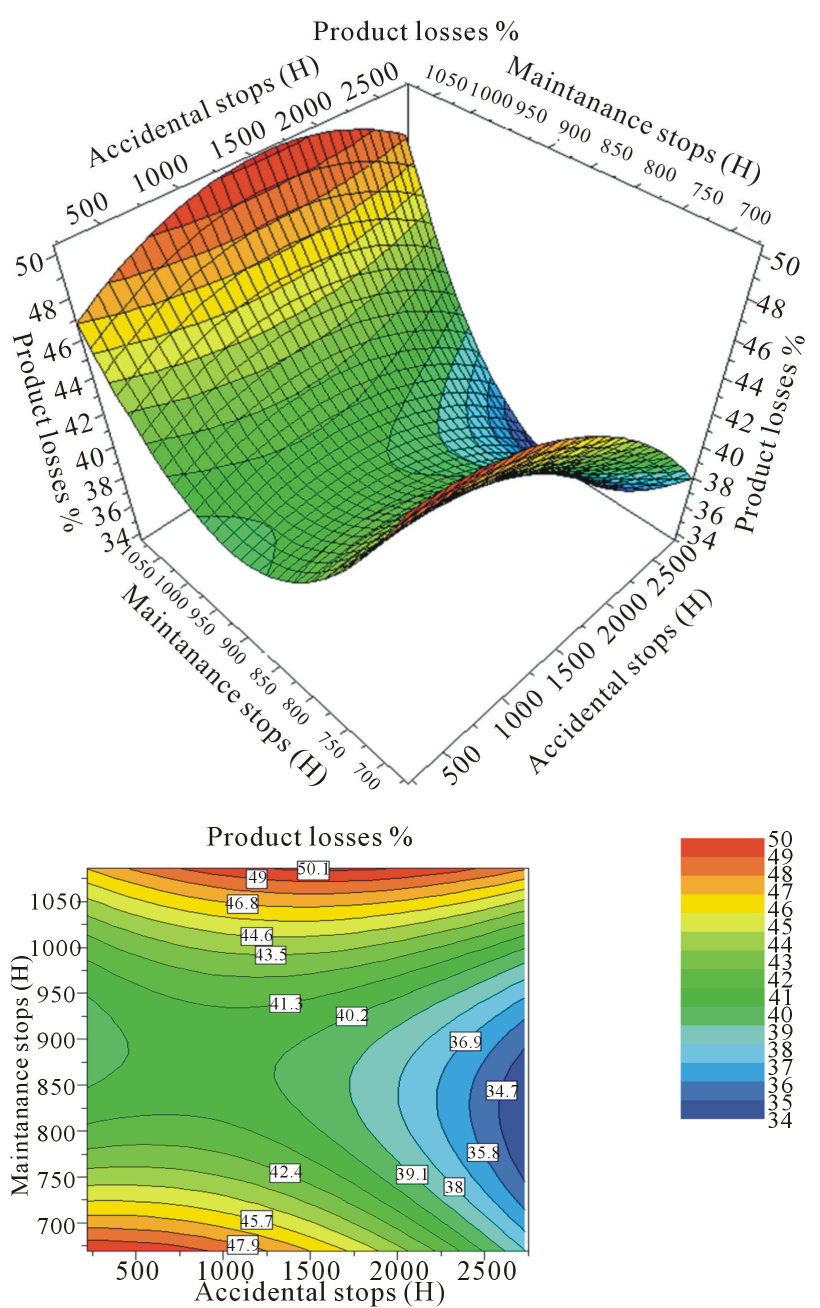

Figure 7. Response surface and ISO response curves when $x_{3}$ is middle.

tacles. In this section, the response " $y$ " remains relatively constant; it varies from $40.5 \%$ to $41.3 \%$ over a large part of the work domain. This shows that we can get the constant value of production losses defined by the $41.3 \%$ by several combinations between accidental stops $\left(x_{1}\right)$ and maintenance and management of human resources stops. Table 5 gives some values of production losses outside the central zone with tentacles.

It is clear, that the columns and rows (Table 5) display for constant values of the parameter $x_{1}$, that production losses decrease in first with increasing parameter $x_{2}$, stabilise at central area of the graph 8 , and subsequently increase. However, when $x_{2}$ remains constant, production losses decrease for the 2 first rows with increasing $x_{1}$, but increase in first and subsequently decrease for the 2 last rows of Table 5 with increasing $x_{1}$.

\section{When $x_{3}$ Is Equal at the High Value ( $x_{3}=9703.75$ Hours)}

When the parameter $x_{3}$ takes its maximum and invariable
Table 5. Production losses in central zone when $x_{3}$ is middle.

\begin{tabular}{cccccc}
\hline$x_{2}$ & $\begin{array}{c}500 \\
\text { hours }\end{array}$ & $\begin{array}{c}1000 \\
\text { hours }\end{array}$ & $\begin{array}{c}1500 \\
\text { hours }\end{array}$ & $\begin{array}{c}2000 \\
\text { hours }\end{array}$ & $\begin{array}{c}2500 \\
\text { hours }\end{array}$ \\
\hline $\begin{array}{c}700 \\
\text { hours }\end{array}$ & $47.4 \%$ & $46.5 \%$ & $44.7 \%$ & $42 \%$ & $38.4 \%$ \\
$\begin{array}{c}750 \\
\text { hours }\end{array}$ & $44.1 \%$ & $43.5 \%$ & $42 \%$ & $39.7 \%$ & $36.4 \%$ \\
1000 & $42.7 \%$ & $43.8 \%$ & $43.9 \%$ & $43.1 \%$ & $41.4 \%$ \\
hours & & & & & \\
1050 & $45.5 \%$ & $46.9 \%$ & $47.3 \%$ & $46.8 \%$ & $45.4 \%$ \\
hours & & & & & \\
\hline
\end{tabular}

value of 9703.75 hours in the mathematical model 4, the responses surface is the concave form upwards (Figure 8). Its projection gives curves ISO responses directed from top to bottom and curved in the centre of the graph. This shows that for a given value of accidental stops $\left(x_{1}\right)$, losses of production vary slowly with the change of stops due to maintenance and human resource management. It is easy to see that for maximum value of $x_{3}=9703.75$ hours, the increase of accidental stops $\left(x_{1}\right)$ reduced the losses of production; this is due to the effect of negative sign of the interaction of parameters $x_{1}$ and $x_{3}$ in the polynomial (4) and equal to $a_{13}=-8.78769$ which reduces considerably the value of the response " $y$ ". One remarks that in passing from value $x_{1}=500$ hours to $x_{1}=2500$ hours for the same value of $x_{2}=900$ hours, losses of production fells from $55.8 \%$ to $22.2 \%$.

\section{Management of Production Waste by Statistical Process Control}

The losses rate of production per lines caused by the various stops does not explain alone the waste of finished products during production process. It is rather frequency of repeated stops that causes restarts manufacturing process. This will requires each time the equipments settings to obtain the finished standardised products. Knowing annual waste rate of polyethylene products for water of $3.15 \%$ and for gas of $2.54 \%$, the average waste rate of 8 lines is:

$$
\text { Waste rate }=\frac{\sum_{i=1}^{n} x_{i}}{n}=2.845 \%
$$

where: $\sum x_{i}$ is sum of distribution values equal to $5.69 \%$; $\mathrm{n}$ is samples number equal to 2 ; this is giving us process quality “ $m$ " or "Yield" of $97.155 \%$ (Figure 9).

This value is considered as the average value of the process target to achieve (average value of distribution). As the value of the standard deviation is sigma equal to 0.9425071, the repetition frequency of production stops is:

$$
f=\frac{1}{\sigma \sqrt{2 \pi}}=0.42328
$$



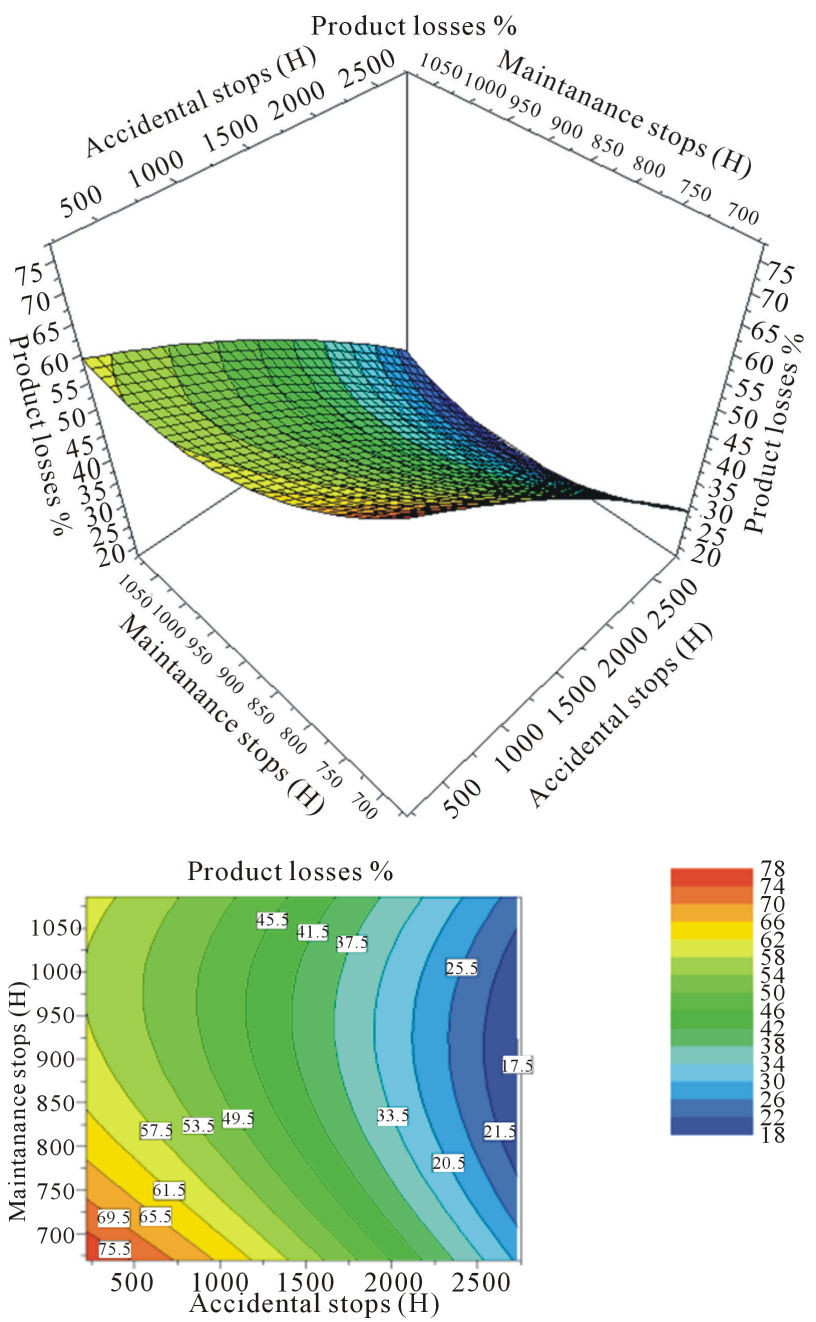

Figure 8. Response surface and ISO response curves when $x_{3}$ is high.

This value is represented by the top of the Gauss curve of production process. It corresponds to $0.91569 \sigma$ on the $\mathrm{X}$ axis and represents the lag due to the production process and waste estimated at 28500 DPMO (defects per millions of opportunities) (Unhatched area of Figure 9). The beginning of waste area corresponding to end of process performance $z$, it is found in the following manner:

$$
Z=\operatorname{coef} \cdot \sigma
$$

where $z$ is sigma process quality; it is calculated with coefficient who taken from the normal distribution taking account the risk of 0.05 and "UCL, LCL" values through manufactured tables (coef $=3.403311$ ); the process performance $z$ is equal at $3.403311 \sigma$. The $\sigma$ value is the standard deviation, it calculated by this formula:

$$
\sigma=\sqrt{\frac{\sum_{1}^{n}\left(x_{i}-m\right)^{2}}{n}}
$$

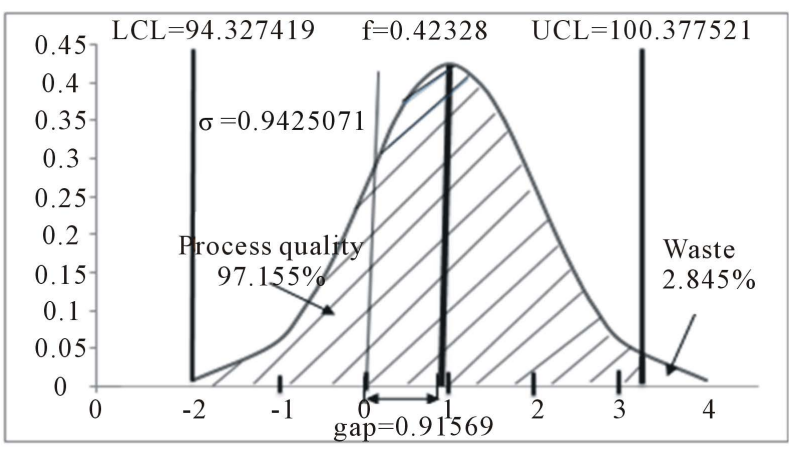

Figure 9. Gauss curve of production losses.

The process performance $z$ is then 3.2076447. The low control limit (LCL) and the upper control limit (UCL) are calculated by this following formula; here, the target is the process quality $m=100 \%-2.845 \%=97.155 \%$ :

$$
\mathrm{LCL}, \mathrm{UCL}=\text { target } \pm 3 \sigma
$$

Their respective values are then 94.327419 and 100.377521. The process quality area of the real production process is thus defined by LCL, UCL and the Gauss curve of normal distribution (hatched zone in Figure 9). It is equal to $97.155 \%$. The combination of two methods of analysis, the experimental design and statistical process control in management showed us that performance of studied process is relatively small compared to a process without stops or waste. The management of waste during the production process is directly linked to the frequency of stops and starts of manufacturing lines. To achieve Six Sigma process with performance of 99.999\%, one must improve the process capability index $C_{p}$ in order to be higher than 2 . However, the capability index of six production lines is $z / 3=1.1344$; the production process of PE is then just capable. To achieve high performance, one must act in several fields that cause the increase of waste. Managing production waste is to understand the real causes that push businessmen to submit program changes on the production lines, and see if there are opportunities for their reductions. It must also understand the real causes of mechanical and electrical failures and assess the reliability of the maintenance planning. Finally know the real causes of non conformities of products and analyse the production process and intervention function responsible for the technical quality. Thereafter take the necessary technical and financial measures and control by means of managerial actions to reduce this waste.

\section{Capability Indices and Process Performance}

The capability indices of process " $C_{p}$ ", of machine " $C_{m}$ " and process performance " $P_{p}$ " are important data that demonstrate the real capacity continuous production pro- 
cess of the manufacturing company of tubes. The capability index that takes account process, machine, and the performance is calculated as follows:

$$
\operatorname{Index}\left(C_{p}, C_{m}, P_{p}\right)=\frac{\mathrm{UCL}-\mathrm{LCL}}{6 \sigma}
$$

The value of this index is then 0,999993 , i.e. close to 1 . The capability index of the process $C_{p}$ is found in the following manner:

$$
C_{p}=\frac{z}{3}=\frac{3.2076447}{3}=1.0692149
$$

The $C_{p}$ index exceeds the value of 1 , but the quality of process $6 \sigma$ requires a capability of process more than 2 . The production process of the tubes is barely capable but is not very efficient. The capability index of Machine $C_{m}$ allows measuring the material resources available the continuous production process of the tubes is able to achieve the target of $99.999966 \%$ of performance; the value of this index is:

$$
\begin{aligned}
& C_{m}=\frac{\mathrm{UCL}-\mathrm{LCL}}{3 \bar{\sigma}} ; \\
& \bar{\sigma}=\sqrt{\frac{\sum_{i=1}^{n}\left(x_{i}-\text { target }\right)^{2}}{n-1} ;} \\
& C_{m}=0.6292
\end{aligned}
$$

The $C_{m}$ index does not exceed 1.11 which allows the reduction of waste of $0.00034 \%$. The tools and machineries of production plant are not capable to achieve performance of $6 \sigma$ quality. The plant must innovate and reduce the variability due to different causes of machine stops.

\section{Conclusion}

Causes analysis of waste by 2 methods statistical process control and design of experiments are a very effective means that can take measures to manage the losses. These methods permit to develop recommendations. They can satisfy demands to achieve the production requirements mastering the controllable factors, reducing the impact of uncontrollable factors, minimising the financial losses and improving the quality of production. The reduction of waste is the result of the reduction of machine stops; this reduction supports the achievement of measurable and non-measurable gains such as reduction of the manufacturing cost and coast of control factors, reduction delay time, improvement employee competence, improvement working environment due to the reduction of machine stops hours. All this will automatically change the profitability of the process and the gains of the company. The performance of production is treated in sigma process quality (performance quality) by Equation (10).

\section{REFERENCES}

[1] P. Bousselet, “The process Computerisation QSE in Agribusiness: The 30 Questions to Consider Quality, Safety and Environment,” PBC Soft, Paris, 2010.

[2] B. Froman, J. M. Gey and F. Bonnifet, "Quality, Safety and Environment: Construct an Integrated Management System,” AFNOR, La Plaine Saint-Denis, 2007.

[3] M. Bernardo, M. Casadesus and S. Karapetrovic, "How Integrated Are Environmental, Quality and Other Standardised Management Systems? An Empirical Study," Journal of Cleaner Production, Vol. 17, No. 8, 2009, pp. 742-750. http://dx.doi.org/10.1016/j.jclepro.2008.11.003

[4] K. R. Bhote, "The Power of Ultimate Six Sigma, Quality Excellence to Total Business Excellence,” Amacom, New York, 2003.

[5] D. Duret and M. Pillet, "Quality in Production: From ISO 9000 to Six Sigma,” 4th Edition, Eyrolles Edition, Paris, 2005.

[6] H. Aadi and B. John, "Hygiene and Safety at Work," Office of Professional Training and Work Promotion, Rabat, 2011.

[7] Fernandez-Toro and A. H. Schauer, "Management of Information Security: Implementing ISO 27001, Implementation of ISMS and Certification Audit," Eyrolles, Paris, 2008.

[8] R. Holdsworth, "Practical Applications Approach to Design, Development and Implementation of an Integrated Management System,” Journal of Hazardous Materials, Vol. 104, No. 1-3, 2003, pp. 193-205. http://dx.doi.org/10.1016/j.jhazmat.2003.08.001

[9] T. H. Jorgensen, A. Remmen and M. D. Mellado, “Integrated Management Systems-Three Levels of Integration,” Journal of Cleaner Production, Vol. 14, 2006, pp. 713-722.

[10] R. Salomone, "Integrated Management Systems: Experiences in Italian Organisations," Journal of Clearner Production, Vol. 16, 2008, pp. 1786-1805. 